\title{
RADIOGRAFIA E MACROSCOPIA DO JOELHO APÓS ESTABILIZAÇÃO EXTRA-ARTICULAR UTILIZANDO FÁSCIA LATA, FIO DE POLIÉSTER TRANÇADO OU FIO DE POLIAMIDA PARA CORREÇÃO DA RUPTURA DO LIGAMENTO CRUZADO CRANIAL EM CÃES
}

\author{
RADIOGRAPH AND MACROSCOPY OF STIFLE JOINT AFTER EXTRA-ARTICULAR \\ STABILIZATION EMPLOYING FASCIA LATA, BRAIDED POLYESTER AND POLYAMIDA \\ TO CORRECT CRANIAL CRUCIATE LIGAMENT RUPTURE IN DOGS
}

\author{
Luiz Eduardo Carvalho Buquera ${ }^{1}$ Júlio Carlos Canola ${ }^{2}$ João Guilherme Padilha Filho ${ }^{2}$ \\ Juliana Maziero Furlani ${ }^{3}$ Ivia Carmem Talieri ${ }^{4}$ André Luiz Selmi $^{4}$
}

RESUMO

A ruptura do ligamento cruzado cranial é uma das principais doenças ortopédicas que afetam os cães. Muitas técnicas cirúrgicas foram descritas no intuito de aliviar a dor, restaurar a estabilidade biomecânica do joelho e prevenir a progressão da osteoartrite. Fáscia lata, fio de poliéster trançado e fio de poliamida foram empregados na estabilização do joelho após excisão do ligamento cruzado cranial em cães, os quais foram submetidos à avaliação radiográfica e macroscópica da articulação. Neste estudo, foram utilizados 18 cães com massa corporal superior a $15 \mathrm{Kg}$ (peso médio - 19,67kg), separados em 3 grupos eqüitativos correspondentes a cada técnica, avaliados durante 30 e 60 dias. Ao exame radiográfico, independentemente de grupo, os cães apresentaram evidência de efusão articular moderada a severa, distensão da cápsula articular e, na maioria dos casos, ausência de sinais de doença articular degenerativa. Ao exame macroscópico da articulação do joelho observou-se espessamento da cápsula articular e tecidos moles periarticulares, erosão da cartilagem articular dos côndilos femorais em todos os grupos e afrouxamento dos fios nos cães submetidos às técnicas de estabilização extra-articular com fio de poliéster trançado e fio de poliamida.

Palavras-chave: cirurgia, radiologia, ortopedia.
SUMMARY

The cranial cruciate ligament rupture is one of the main orthopaedic diseases which affect dogs. Many surgical techniques have been described and they aim to relief the pain, restore stifle biomechanical stability and prevent the progression of osteoarthritis. Fascia lata, braided polyester and polyamida were used in lateral fabellar suture to stifle stabilization after induced cranial cruciate ligament rupture in dogs that were submitted to radiographic and macroscopic evaluation of joint. In this study 18 dogs weighting more than $15 \mathrm{~kg}$ were used (middleweight - 19.67kg), distributed in three groups corresponding to each technique, evaluated during 30 and 60 days. In the radiographic exam, the dogs had evidence of moderate to severe joint effusion, capsular distension and, in most cases, lacking of degenerative articular disease features. At the macroscopic exam of the stifle joint thickening of the joint capsule and periarticular soft tissues, erosion of the femoral condyles cartilage in all groups and loosening of the suture were observed in dogs submitted to extra-articular stabilization techniques employing braided polyester and polyamida.

Key words: surgery, radiology, orthopaedics.

\section{INTRODUÇÃO}

A ruptura do ligamento cruzado cranial (RLCCr) é uma das injúrias mais freqüentes no cão,

\footnotetext{
${ }^{1}$ Médico Veterinário, Doutorando do Curso de Pós-graduação em Cirurgia Veterinária, Faculdade de Ciências Agrárias e Veterinárias (FCAV), Universidade Estadual de São Paulo (UNESP), Via de Acesso Prof. Paulo Donato Castelanne Km 5, 14884-900, Jaboticabal, SP.E-mail: buquera@zipmail.com.br. Autor para correspondência.

${ }^{2}$ Médico Veterinário, Professor Assistente, Doutor do Departamento de Clínica e Cirurgia Veterinária, FCAV/UNESP, Jaboticabal, SP.

${ }_{3}^{3}$ Médico Veterinário, Aprimoranda em Cirurgia de Pequenos Animais do Hospital Veterinário, FCAV/UNESP, Jaboticabal, SP.

${ }^{4}$ Médico Veterinário, Doutorando do Curso de Pós-graduação em Cirurgia Veterinária, FCAV/UNESP, Jaboticabal, SP.

Recebido para publicação em 29.12.00. Aprovado em 23.05.01
} 
sendo a principal causa de doença articular degenerativa do joelho nessa espécie (BRINKER $\boldsymbol{e t}$ al., 1986). O ligamento cruzado cranial (LCCr) é responsável pela manutenção da estabilidade crâniocaudal e rotacional do joelho (ARNOCZKY, 1996; MOORE \& READ, 1996a). A RLCCr tem sido identificada em cães de todas as raças, idades e tamanhos (RACKARD,1996). BRINKER et al. (1986) citam lesão de menisco em aproximadamente $50 \%$ dos casos de RLCCr.

De acordo com ARNOCZKY (1996), embora possa ocorrer ruptura aguda do $\mathrm{LCCr}$, supõe-se que a maioria das lesões seja resultante de alterações degenerativas crônicas nos próprios ligamentos. WHITEHAIR et al. (1993) sugerem que a conformação anormal da tíbia, doenças imunomediadas e obesidade são condições que contribuem para a degeneração do LCCr.

O exame físico revela atrofia muscular da coxa, crepitação ao movimento de flexão e extensão do joelho, efusão articular e, em casos crônicos, espessamento da cápsula articular medial. O diagnóstico geralmente é feito ao exame físico, por meio dos testes de movimento de "gaveta" cranial ou compressão tibial (HULSE, 1995; MOORE \& READ, 1996b; RACKARD, 1996). O exame radiográfico não é essencial para o diagnóstico da RLCCr, embora ajude a descartar anormalidades ósseas ou dos tecidos moles, bem como documentar o grau de osteoartrite (MOORE \& READ, 1996b; RACKARD, 1996). Os achados radiográficos em pacientes com rompimento crônico do ligamento incluem: formação de osteófitos ao longo das bordas trocleares, superfície caudal do platô tibial e pólo inferior da patela, espessamento da cápsula articular medial e esclerose óssea subcondral (HULSE, 1995; RACKARD, 1996).

As terapias conservativa e cirúrgica são descritas (BRINKER et al., 1986; RACKARD, 1996). Vasseur apud MOORE \& READ (1996b), afirma que o tratamento conservativo (repouso e uso de antiinflamatórios não-esteróides) apresentou bons resultados em cães com massa corporal inferior a $15 \mathrm{~kg}$. A instabilidade resultante da insuficiência do LCCr conduz a alterações degenerativas progressivas dentro de poucas semanas. Este fato justifica o reparo cirúrgico do LCCr objetivando a correção da instabilidade articular e alívio da dor aguda (BRINKER $\boldsymbol{e} \boldsymbol{t}$ al., 1986; RACKARD, 1996).

Existem mais de 100 técnicas cirúrgicas descritas para tratamento da RLCCr, divididas em duas grandes categorias: extra-articulares e intraarticulares (CHAUVET et al., 1996; MOORE \& READ, 1996b; RACKARD, 1996).
A maioria dos métodos extra-articulares baseia-se na utilização de material de sutura de grosso calibre para imbricar a articulação e restaurar a estabilidade (RACKARD, 1996), que é atribuída ao espessamento da cápsula articular e do retináculo, devido à inflamação da ferida cirúrgica e das suturas implantadas (BRINKER et $\boldsymbol{a l}$., 1986; MOORE \& READ, 1996b). DEANGELIS \& LAU (1970) descreveram uma técnica extra-articular, empregando material de sutura inabsorvível de grosso calibre ao redor da fabela lateral e na extremidade distal do ligamento reto patelar. Foram descritas muitas modificações da técnica de DEANGELIS \& LAU (1970) com resultados clínicos similares (MOORE \& READ, 1996b). Enquanto as técnicas extra-articulares estabilizam a articulação pela alteração da posição de estruturas extra-articulares, os métodos intra-articulares substituem o LCCr com algum tipo de enxerto ou material sintético (MOORE \& READ, 1996b; RACKARD, 1996).

Independentemente da técnica cirúrgica escolhida, a taxa de sucesso clínico é próxima a $90 \%$ (HULSE, 1995; MOORE \& READ, 1996b). Nenhuma das técnicas extra ou intra-articulares interrompem a progressão da osteoartrite (ELKINS et al., 1991).

O presente estudo teve como objetivo submeter à avaliação radiográfica e macroscópica as técnicas de sutura fabelar lateral com três diferentes tipos de materiais em cães.

\section{MATERIAL E MÉTODOS}

Utilizaram-se 18 cães hígidos, sem raça definida, adultos, machos e fêmeas com massa corpórea variando entre 15,3 e $33 \mathrm{~kg}$, fornecidos pelo Canil de Experimentação da Faculdade de Ciências Agrárias e Veterinárias - UNESP - Jaboticabal. Os animais foram submetidos à vacinação e vermifugação, identificados e mantidos em canis individuais, com ração e água ad libitum. Os cães foram separados aleatoriamente em 3 grupos, cada qual constituído por seis animais. No grupo I (GI), empregou-se fáscia lata autógena na reparação extraarticular da secção experimental do ligamento cruzado cranial (LCCr), no grupo II (GII) utilizou-se fio de poliéster trançado e no grupo III, (GIII) fio de poliamida.

Após jejum hídrico e alimentar de 12 horas, os cães receberam ampicilina sódica e benzatina $^{\mathrm{a}}(22 \mathrm{mg} / \mathrm{kg}$, por via subcutânea), em período prévio de 30 minutos à indução anestésica. Foram, então, submetidos à medicação préanestésica (MPA), com levomepromazina ${ }^{\mathrm{b}}$ 
$(1 \mathrm{mg} / \mathrm{kg})$, por via intravenosa. Procedeu-se a tricotomia do membro pélvico esquerdo, do terço proximal do fêmur até o terço médio da tíbia. Após 15 minutos da MPA, seguiu-se a indução anestésica com tiopental sódico ${ }^{\mathrm{c}}$ na dose média de $12,5 \mathrm{mg} / \mathrm{kg}$, por via intravenosa. A manutenção anestésica foi feita com halotano ${ }^{\mathrm{d}}$ diluído em oxigênio, administrado por sonda endotraqueal, em circuito semi-fechado, em concentração suficiente para manter o animal no $2^{\mathrm{o}}$ plano do III estádio de Guedel. Estando os animais sob efeito anestésico, foram posicionados em decúbito dorsal. A antisepsia da região foi realizada com solução de polivinil pirrolidona iodo $10 \% \mathrm{e}$.

A abordagem lateral à articulação do joelho baseou-se na técnica cirúrgica descrita por PIERMATTEI \& GREELEY (1988). Com a articulação exposta, procedeu-se excisão do coxim adiposo infrapatelar, para a inspeção dos meniscos e ligamentos cruzados. Removeu-se o LCCr após incisão das suas inserções femoral e tibial. A cápsula articular foi suturada com náilon monofilamentado ${ }^{f}$ empregando padrão contínuo simples em todos os animais.

Nos animais do GI, as incisões de pele, tecido subcutâneo e fáscia lata estenderam-se até o terço médio do fêmur. Na fáscia lata, procedeu-se incisão paralela à primeira, produzindo-se uma tira de largura variável (1,5 a 2,5cm aproximadamente), que foi liberada na sua inserção proximal e rebatida distalmente até a altura da tuberosidade da tíbia. A seguir, esta tira foi passada ao redor do tendão do músculo gastrocnêmio e suturada à sua inserção, próxima à tuberosidade da tíbia, com poliamida ${ }^{\mathrm{g}} \mathrm{em}$ padrão interrompido simples. Para tal, o membro foi fixado em posição anatômica e o auto-enxerto esticado ao máximo. Foram colocados alguns pontos de poliamida $0,40 \mathrm{~mm}$ entre o tendão do músculo gastrocnêmio e a tira de fáscia lata, com o objetivo de impedir o deslocamento caudal da última. O procedimento sobredito baseia-se na técnica descrita por AIKEN et al. (1992), com uma pequena modificação (a tira de fáscia lata foi passada ao redor do tendão do músculo gastrocnêmio em vez de ser passada através de um túnel produzido no mesmo tendão, como preconizado na técnica original).

Nos animais do GII, um fio de poliéster trançado $^{\mathrm{h}}$ equivalente ao cirúrgico $\mathrm{n}^{\mathrm{o}} 5$, foi passado com agulha curva ao redor do ligamento fabelofemoral e por orifício transversal criado na crista da tíbia com furadeira e pino intramedular de $1 \mathrm{~mm}$. O nó foi cerrado na face lateral do joelho. Nos animais do GIII, o procedimento foi executado da mesma forma que nos animais do GII, utilizando-se fio de poliamida ${ }^{\mathrm{i}}$, em vez de fio de poliéster trançado.
O defeito produzido na fáscia lata foi suturado com poliamida $0,40 \mathrm{~mm}$ em padrão interrompido simples. A seguir, fez-se injeção intra-

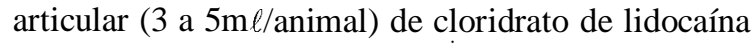
$2 \%$ com epinefrina $-1: 200.000^{\mathrm{j}}$, com a finalidade de controlar a dor pós-operatória. Nos três grupos, o tecido subcutâneo foi reaproximado em padrão contínuo simples, com categute simples ${ }^{\mathrm{k}}$ e a pele em padrão interrompido simples, com poliamida.

No período pós-operatório, colocou-se bandagem de faixa de crepe e esparadrapo no membro operado e colar tipo "elizabetano" no animal, durante 5 e 15 dias, respectivamente. Administraram-se flunixin meglumine ${ }^{\mathrm{m}}(1,1 \mathrm{mg} / \mathrm{kg}$ a cada 24 horas), cetoprofeno ${ }^{\mathrm{n}}(2,2 \mathrm{mg} / \mathrm{kg}$ a cada 24 horas) ou carprofeno ${ }^{\circ}(2,2 \mathrm{mg} / \mathrm{kg}$ a cada 12 horas $)$, subdivididos igualmente entre os grupos, durante quatro dias desde o período pré-operatório. $\mathrm{O}$ curativo da ferida cirúrgica foi realizado com "spray" à base de rifamicina ${ }^{\mathrm{p}}$, até a completa cicatrização.

Objetivando graduar a doença articular degenerativa (DAD), o joelho esquerdo foi submetido a exame radiográfico nas posições crâniocaudal e médio-lateral no período pré-operatório para controle, aos 30 dias de pós-operatório em todos os animais e, aos 60 dias de pós-operatório, em metade dos animais de cada grupo. Os cães foram anestesiados com associação de acepromazina $^{\mathrm{q}}(0,1 \mathrm{mg} / \mathrm{kg})$ e tiletamina-zolazepam ${ }^{\mathrm{r}}$ $(5 \mathrm{mg} / \mathrm{kg})$, administrados por via intravenosa. Foi estabelecida classificação dos cães quanto ao grau de doença articular degenerativa, considerando todos os sinais radiográficos presentes, em animais normais ou portadores de grau leve, moderado e severo.

A avaliação macroscópica da articulação do joelho foi executada em nove animais, sendo três de cada grupo, com a finalidade de observar a integridade dos meniscos, tecidos moles periarticulares e superfícies articulares. A determinação dos períodos de observação (30 ou 60 dias) não ocorreu de forma sistemática, pois deu-se prioridade à manutenção da vida dos cães sempre que fosse possível encontrar pessoas interessadas em adotá-los. A avaliação macroscópica foi procedida em sete cães que não foram adotados, independentemente de grupo, após sacrifício. Em outros dois cães a avaliação macroscópica se deu por artrotomia exploratória com a finalidade de completar três animais em cada grupo. A artrotomia exploratória não foi executada em todos os cães, pois as poucas oportunidades de adoção poderiam ser inviabilizadas, se fosse solicitado aos interessados que esperassem o período adicional de recuperação. 


\section{RESULTADOS}

Efusão infra-patelar moderada a severa, distensão de cápsula articular e, na maioria dos casos, ausência de sinais de DAD foram as características observadas no exame radiográfico. Não obstante, os animais 5 e 6 do GII exibiram subluxação cranial da tíbia, e o animal 4, do mesmo grupo, grau leve de DAD aos 60 dias de avaliação. $\mathrm{O}$ animal 5 do G III apresentou DAD moderada. Os animais 3 do GII e 6 do GIII manifestaram osteófitos no pólo inferior da patela. Espessamento do ligamento reto patelar foi verificado em cães de todos os grupos. Os cães do GI não demonstraram indícios da instalação de doença articular degenerativa.

Macroscopicamente, não foram observadas alterações nos meniscos dos cães avaliados. Espessamento da cápsula articular e tecidos moles periarticulares foram as alterações mais frequientes. Relativamente à superfície articular, a erosão da cartilagem articular lateral dos côndilos femorais foi a alteração mais presente, independentemente de grupo. Osteófitos foram evidenciados em três dos nove animais avaliados, sendo um de cada grupo. Dois cães entre os avaliados, apresentaram afrouxamento do fio empregado na sutura anti-rotacional (um do Gll e outro do Glll) e num terceiro (do Glll) o fio de poliamida soltou-se da posição ao redor da fabela lateral.

\section{DISCUSSÃO}

A escolha de técnicas de sutura fabelar lateral para estabilização do joelho, baseou-se na facilidade de execução, com resultados similares ou superiores às técnicas intra-articulares e à transposição da cabeça da fíbula em cães com mais de $15 \mathrm{~kg}$, como demonstrado por DEANGELIS \& LAU (1970), OLMSTEAD (1993) e CHAUVET $\boldsymbol{e}$ al. (1996). O acesso cirúrgico lateral à articulação do joelho, preconizado por PIERMATTEI \& GREELEY (1988), foi adequado para a realização das técnicas propostas no presente estudo.

VASSEUR \& BERRY (1992) enfatizam que o exame radiográfico é uma mensuração objetiva da DAD secundária à instabilidade articular e que a capacidade de manter a biologia normal da articulação, prevenindo a DAD secundária, revela-se o verdadeiro teste para qualquer técnica cirúrgica de reparo do LCCr. Consideram ainda que o grau de claudicação e o movimento de gaveta são indicadores incertos para avaliação das técnicas cirúrgicas a longo prazo. Não obstante, CHAUVET et al. (1996) afirmam que nenhum procedimento cirúrgico foi capaz de prevenir a progressão da DAD, dificultando a escolha da terapia mais adequada por meio deste critério. No presente estudo, o curto período de avaliação radiográfica impede que os resultados relativos à presença de DAD constituam, isoladamente, um meio seguro para determinação da técnica cirúrgica mais adequada. Desse modo, a utilização de indicadores como o grau de claudicação e movimento de gaveta em associação à avaliação radiográfica, continua sendo indispensável.

Efusão articular e distensão da cápsula articular são achados radiográficos consistentes com ruptura do LCCR, como constatado por BRINKER et al. (1986), RACKARD (1996) e MOORE \& READ (1996a).

Apesar de a formação de osteófitos não ser necessariamente um sinal de alterações degenerativas na cartilagem articular, sua constatação é utilizada rotineiramente como critério principal para o diagnóstico de osteoartrite. Osteófitos periarticulares podem ser observados, macroscopicamente, 14 dias após injúria, e detectados ao exame radiográfico, aos 21 dias após a lesão (ELKINS et al., 1991). Paatsama \& Sittinikow e Gilbertson apud BENNETT et al. (1988), em estudo radiográfico, observaram osteófitos três semanas após a secção experimental do LCCr. No presente estudo, a estabilização cirúrgica da articulação, seguindo-se à ruptura induzida do ligamento cruzado cranial, retardou o aparecimento de sinais radiográficos de $\mathrm{DAD}$, pois em 60 dias de observação, apenas dois de 18 animais apresentaram osteófitos. Cabe ressaltar que ambos apresentaram joelhos menos estáveis que os outros cães ao teste do movimento cranial de gaveta e que não foi possível estabelecer relação entre a presença de osteófitos com a deambulação dos animais.

A progressão da degeneração articular, observada no estudo de VASSEUR \& BERRY (1992) indica a incapacidade do procedimento cirúrgico (técnica "under-and-over") fornecer estabilidade articular ou a persistência dos processos patológicos que contribuíram para a RLCCr. Segundo o mesmo autor, esses achados foram similares aos de outros estudos que empregaram a mesma técnica cirúrgica, bem como outras técnicas intra-articulares e extra-articulares. No presente estudo, a inexistência de DAD ou aparecimento de sinais discretos com evolução lenta, foram atribuídos à realização imediata de procedimento cirúrgico visando à estabilização da articulação, ausência de processos patológicos pré-existentes e confinamento dos cães.

Ciência Rural, v. 32, n. 1, 2002. 
O afrouxamento das suturas extraarticulares de poliéster trançado e poliamida, assim como a soltura do fio de poliamida, atribuída à fixação inadequada (o fio deve ser ancorado ao ligamento fabelo-femoral e a um túnel na tuberosidade de tíbia e o nó cerrado lateralmente ao joelho), observados no presente estudo, foram previstos por AIKEN et al. (1992), motivo que os levou a utilizar fáscia lata autógena na sutura antirotacional em cães com menos de $15 \mathrm{~kg}$.

A ausência de lesões de menisco, a despeito da alta incidência em casos clínicos de RLCCr (50 a 70\%) relatada por BRINKER et al. (1986) e OLMSTEAD (1993), justifica-se pela estabilização imediata do joelho após indução da RLCCr, confinamento dos cães, exercício restrito, além do pequeno período de observação (60 dias). Em excisões experimentais do LCCr, observou-se lesão do menisco medial em torno de $50 \%$ dos cães após seis meses (FLO, 1993).

A erosão da cartilagem articular verificada neste estudo, pode estar relacionada ao atrito do material de sutura inabsorvível, empregado na cápsula, com as superfícies articulares, segundo BRINKER et al. (1986), ou então, pode fazer parte unicamente do processo de osteoartrite, devido à algum grau de instabilidade articular, que no presente estudo foi avaliada por meio do teste do movimento cranial de gaveta.

\section{CONCLUSÃO}

As técnicas de sutura fabelar lateral foram adequadas para correção de instabilidade articular provocada por RLCCr, em cães com massa corporal superior a $15 \mathrm{~kg}$, avaliados até 60 dias de pósoperatório. O GI apresentou menor incidência de DAD ao exame radiográfico que os observados nos grupos GII e GIII aos 30 e 60 dias de avaliação, porém qualquer afirmação quanto à superioridade de um dos materiais só poderia ser feita se esses resultados fossem associados a achados clínicos favoráveis. A extrapolação dos resultados experimentais para a rotina clínica nem sempre é possível e deve ser feita com cautela, pois eventos como a instabilidade crônica e alterações degenerativas pré-existentes presentes nos casos clínicos, não podem ser desconsiderados. A realização de estudos radiográficos adicionais por período mais prolongado seriam úteis para fornecer informações mais consistentes no que tange ao desenvolvimento de doença articular degenerativa. Os resultados obtidos pela avaliação macroscópica não permitiram a comparação entre os materiais testados, principalmente quanto ao período da observação devido ao "n" reduzido e distribuição irregular dos cães. No máximo, pode-se verificar que os achados da avaliação macroscópica foram similares nos nove cães avaliados, independentemente de grupo e período de observação.

\section{FONTES DE AQUISIÇÃO}

A Optacilin. BYK Química e Farmacêutica Ltda. Diadema, SP. b Neozine. Rhodia. São Paulo, SP.

c Tiopental 1g. Cristalia - Produtos Químicos Farmacêuticos Ltda. Itapira, SP.

d Halotano. Hoechst do Brasil. Itapira, SP.

e Riodeine Tópico. Indústria Farmacêutica Rioquímica Ltda. São José do Rio Preto, SP.

f Mononylon 2-0. Johnson \& Johnson Produtos Profissionais Ltda. São José dos Campos, SP.

G Náilon de Pesca 0,40 mm. Mazzaferro Polímeros e Fibras Sintéticas Ltda. São Bernardo do Campo, SP.

h Poliéster Trançado ref. 248.12. Fábrica de Tranças Brasil Ltda. São Paulo, SP.

i Náilon de Pesca 0,60mm. Mazzaferro Polímeros e Fibras Sintéticas Ltda. São Bernardo do Campo, SP.

j Xylestesin. Cristália-Produtos Químicos Farmacêuticos Ltda. Itapira, SP.

k. Catgut Simples 2-0. Cirumédica - Brasil. Cotia, SP.

1. Náilon de Pesca 0,25mm. Mazzaferro Polímeros e Fibras Sintéticas Ltda. São Bernardo do Campo, SP.

$\mathrm{m}$ Banamine. Schering-Plough Veterinária. Rio de Janeiro, RJ.

n Ketofen. Merial. Paulínia, SP.

o Rimadyl. Pfizer. Guarulhos, SP.

p Rifocina spray. Hoechst Marion Roussel. Suzano, SP.

q Acepran . Univet S.A. Ind. Veterinária. São Paulo, SP.

r Zoletil. Virbac do Brasil. São Paulo, SP.

\section{REFERÊNCIAS BIBLIOGRÁFICAS}

AIKEN, S.W.; BAUER, M.S; TOOMBS, J.P. Extra-articular fascial strip repair of the cranial cruciate deficient stifle: technique and results in seven dogs. Vet Comp Orthop Traumatol, Stuttgart, v.5, n.4, p.145-150, 1992.

ARNOCZKY, S.P. Patomecânica das lesões do ligamento cruzado e meniscos. In: BOJRAB, M. J. Mecanismos da moléstia de pequenos animais. 2.ed. São Paulo : Manole, 1996. Cap.110, p.889-902.

BENNETT, D.; TENNANT, B.; LEWIS, D.G., $\boldsymbol{e}$ t $\boldsymbol{a}$. A reppraisal of anterior cruciate ligament disease in the dog. J Small Anim Pract, Londres, v.29, n.5, p.275-297, 1988.

BRINKER, W.O.; PIERMATTEI, D.L.; FLO, G.L. Manual de ortopedia e tratamento das fraturas dos pequenos animais. São Paulo : Manole, 1986. Cap.20, p.324-333.

CHAUVET, A.E.; JOHNSON, A.L.; PIJANOWSKI, G.J., et al. Evaluation of fibular head transposition, lateral fabellar suture, and conservative treatment of cranial cruciate ligament rupture in large dogs: a retrospective study. J Am Anim Hosp Assoc, Denver, v.32, n.3, p.247-255,1996.

DEANGELIS, M.; LAU, R.E. A lateral retinacular imbrication technique for the surgical correction of anterior cruciate ligament rupture in the dog. J Am Vet Med Assoc, Schaumburg, v.157, n.1, p.79-84, 1970. 
ELKINS, A.D.; PECHMAN, R.; KEARNEY, M.T., et al. A retrospective study evaluating the degree of degenerative joint disease in the stifle joint of dogs following surgical repair of anterior cruciate ligament rupture. J Am Anim Hosp Assoc, Denver, v.27, n.5, p.533-540, 1991.

FLO, G.L. Meniscal Injuries. Vet Clin North Am Small Anim Pract, Philadelphia, v.23, n.4, p.831-843, 1993.

HULSE, D.A. Ligament injuries of the stifle joint. In: OLMSTEAD, M.L. Small animal orthopedics. St. Louis : Mosby Year Book, 1995. Cap.18, p.404-411.

MOORE, K.W.; READ, R.A. Rupture of the cranial cruciate ligament in dogs - part I. Comp Cont Educ Pract Vet, Auburn, v.18, n.3, p.223-234, 1996a.

MOORE, K.W.; READ, R.A. Rupture of the cranial cruciate ligament in dogs - part II - diagnosis and management. Comp Cont Educ Pract Vet, Auburn, v.18, n.4, p.381-391, 1996b.
OLMSTEAD, M.L. The use of orthopedic wire as a lateral suture for the stifle stabilization. Vet Clin North Am Small Anim Pract, Philadelphia, v.23, n.4, p.735-753, 1993.

PIERMATTEI, D.L.; GREELEY, R.G. Atlas de abordagens cirúrgicas aos ossos do cão e gato. 2.ed. São Paulo : Manole, 1988. p.164-165.

RACKARD, S. Cranial cruciate ligament rupture in the dog. Irish Vet J, Dublin, v.49, n.7, p.481-484, 1996.

VASSEUR, P.B.; BERRY, C.R. Progression of stifle osteoarthrosis following reconstruction of the cranial cruciate ligament in 21 dogs. J Am Anim Hosp Assoc, Denver, v.28, n.2, p.129-136, 1992.

WHITEHAIR, J.G.; VASSEUR, P.B.; WILLITS, N.H Epidemiology of cranial cruciate ligament rupture in dogs. J Am Vet Med Assoc, Schaumburg, v.203, n.7, p.1016-1019, 1993. 